\title{
Radio-Frequency Assisted Liposuction (RFAL)
}

\author{
Guillermo Blugerman et al.*, \\ 1,3 Argentina
}

\section{Introduction}

The increased prevalence of obesity worldwide has grown the body contouring market, as patients demand more solutions. One of the most popular body contouring methods is liposuction. Pioneered in Europe in the early 1980's as a simple fat aspirating technique, liposuction has quickly expanded its breadth to incorporate a variety of energy sources and modus operandi.

Many types of energies have been combined with standard liposuction techniques in an attempt to improve and optimize treatment outcomes. The current chapter is dedicated to the authors' experience with the most recent addition to the liposuction family, RadioFrequency Assisted Liposuction (RFAL). RFAL delivers RF energy for a thermal effect to the adipose tissue, skin and sub-dermal matrix in a minimally invasive manner.

Enhancing the standard lipoplasty experience with a safe and consistent thermal influence provides the following key benefits:

- Blood vessel coagulation to reduce patient downtime through less bleeding and bruising.

- Tissue tightening to expand the range of patients to now include individuals who are obese and/or have compromised skin conditions (lax skin).

- Increased patient comfort and safety will increase consumer acceptance.

- $\quad$ Reduced procedure time and ease of treatment will increase physician acceptance.

\subsection{Earlier techniques}

In previous years the liposuction procedure has stimulated the development of energy assisted lipoplasty methods, such as power-assisted lipoplasty (PAL), ultrasound-assisted lipoplasty (UAL), and laser-assisted lipoplasty (LAL).

PAL uses a reciprocating cannula that mechanically destroys the subcutaneous tissue through small rapid vibrations. This innovation was developed to accelerate the liposuction

\footnotetext{
"Malcolm D. Paul2, Diego Schavelzon ${ }^{3}$, R. Stephen Mulholland4, Matthias Sandhoffer", Peter Lisborg6, Antonio Rusciani', Mark Divaris ${ }^{8}$, Michael Kreindel ${ }^{9}$,

${ }_{1,3}$ Centros BES de Excelencia en Cirugía Plastica, Buenos Aires, Argentina

${ }^{2}$ Aesthetic and Plastic Surgery Institute, University of California, Irvine, CA, USA

${ }^{4}$ SpaMedica Clinics, Toronto, Canada

${ }^{5}$ Astetische Dermatologie Dr. Sanhofer, Linz, Austria

${ }^{6}$ PrivatKlinik Lisborg \& Parner, Klagenfurt, Austria

7 Skinlaser, Roma,Italy

${ }^{8}$ Institut de Stomatologie, Chirurgie Plastique et Chirurgie Maxillo-Faciale (Université Paris VI) France

${ }^{9}$ Invasix Inc. Toronto, Canada
} 
process, minimize the surgeon's physical exertion and reduce patient downtime post surgery. A 15 patient study comparing PAL to standard liposuction demonstrated that PAL allowed for a faster suction removal without compromising aesthetic contour [1].

UAL has gained popularity over the past two decades especially in the niche market of male patients and as a secondary liposuction procedure. Through the cavitation of the tissue by ultrasonic energy, physicians can better treat more fibrotic tissue and perform more selective fat aspiration. However, UAL did lengthen procedure treatment time as port protectors needed to be incorporated and removed during each treatment. Port protectors increased incision size and often had to be stitched close. In addition, UAL was a two stage procedure, treatment then aspiration, which further lengthened surgeon OR time. Lastly, while treatment outcomes were satisfactory, the subsequent tightening effects of the treated area were similar to that of standard liposuction.

Laser-assisted liposuction provides a thermal experience to the skin to significantly impact dermal contraction. Dr. Barry DiBernardo's randomized blind split abdomen study, "Evaluation of shrinkage and skin tightening in laser lipolysis vs liposuction", determined that placing a laser under the skin and reaching a temperature of $42^{\circ} \mathrm{C}$ can result in a $17 \%$ tightening and area contraction of the skin [2].

\section{Technology and procedure description}

RFAL is the newest entry to the liposuction family and can be found in the BodyTite device (Invasix Ltd., Israel). RFAL deploys RF energy through a hand piece [Figure 1] to deliver a thermal effect to the adipose tissue, skin and sub-dermal matrix.

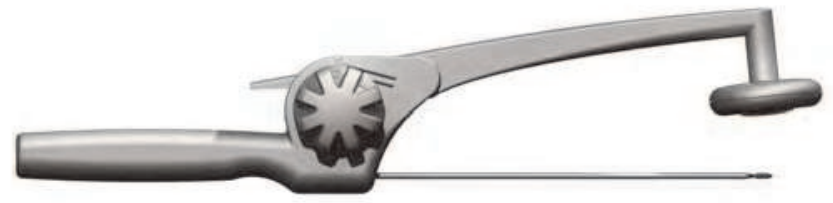

Fig. 1. Schematic presentation of the bi-polar RF hand piece.

RFAL technology uses external and internal electrode, connected by a handpiece, to create a thermal profile. During treatment the internal cannula is introduced into the adipose tissue and can be adjusted for the desired depth of treatment. This adjustment can control the distance between electrodes in the range of $5 \mathrm{~mm}$ to $50 \mathrm{~mm}$ that allows for targeted treatment depth and uniform treatment by layers. Contact is maintained between the external electrode and the skin by a spring-loaded pivot.

When powered, the insulated internal electrode emits RF current through a small conductive tip. The external electrode has a larger contact area and is applied to the skin surface creating a lower power density in the skin than in the adipose tissue [Figure 2]. Up to $75 \mathrm{~W}$ of RF power can be applied between the two electrodes depending on thickness and curvature of treated area. For large and medium volume treatment, the melted fat can be aspirated; for the treatment of small areas, such as the neck and face, the fat may be dissolved naturally through phagocytosis. 
The BodyTite system provides real-time monitoring of the skin temperature and a power cut-off mechanism [Figure 3]. Typical cut-off temperature is in the range of $38-42^{\circ} \mathrm{C}$. When the desired temperature is reached during treatment, the system automatically turns the RF energy off to avoid overheating and ensure the maintenance of uniform temperature over the treated area. If the temperature in the zone starts to drop, or when the hand piece moves to a new zone with a lower temperature, the RF energy becomes active again. The cut-off temperature should be modified depending on the treatment area and the amount of thermal energy required for various zone and skin thicknesses. In addition, it can be adjusted to tailor to more aggressive or conservative approaches.

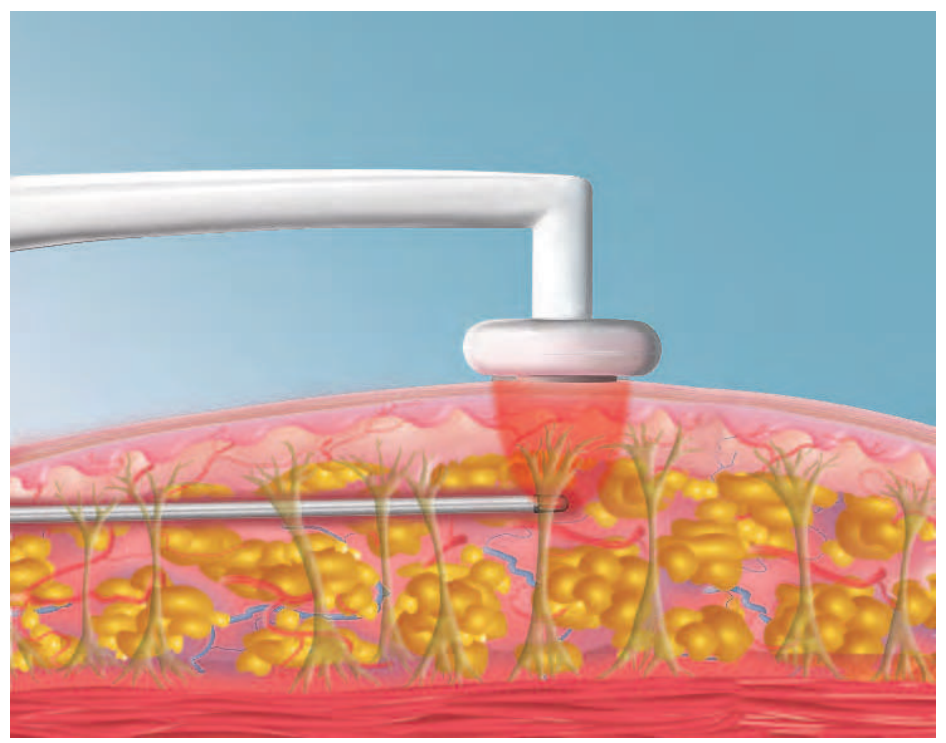

Fig. 2. RFAL hand piece inserted into the body with directional energy applied to adipose fat and septae.
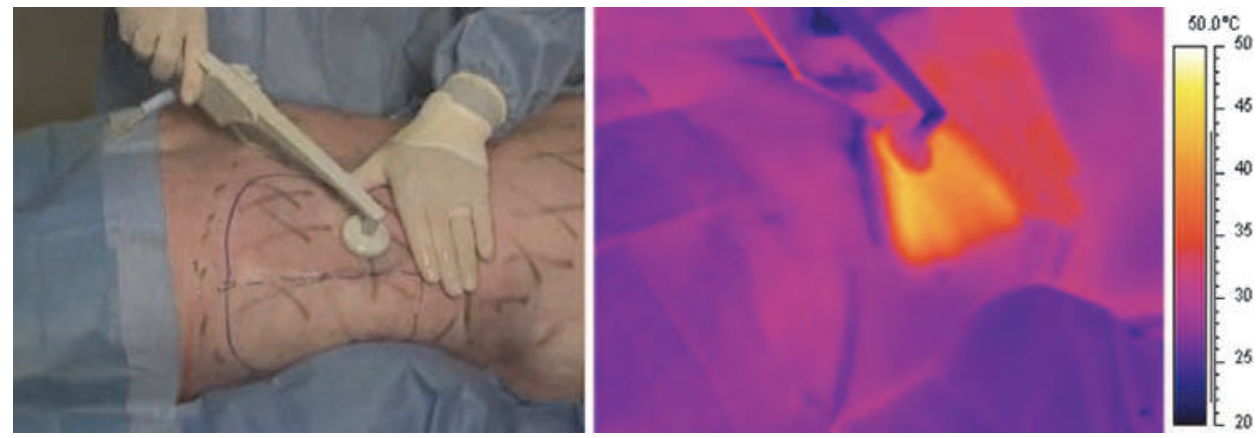

Fig. 3. RFAL uniform thermal distribution without hot spots or under-treated areas resulting from the use of a cut-off temperature control mechanism. 
In addition to emitting energy, the internal electrode also serves as a cannula to provide simultaneous aspiration of the coagulated tissue. Often this coagulated tissue has less hematocrit compared to standard or power assisted liposuction, providing for less bruising post-surgery. [3] Simultaneous aspiration immediately removes treated fat from the treatment site and allows the physician to perform desired contouring, thereby reducing procedure time and associated operating costs.

To appeal to the varied areas of treatment and physician preferences, a number of RFAL hand pieces are available with multiple lengths, diameters, tip configurations, and aspiration ports allowing RFAL to be adapted to different areas and procedures.

Depending on the volume of the body, the procedure can be conducted under general anesthesia, IV sedation or local anesthesia only.

RFAL mainly comprises of the following steps:

- Patient marking of thermal zones $(10 \times 15 \mathrm{~cm})$ and planning of incision ports.

- Applying tumescent anesthesia 30-60 minutes prior the treatment. Common methods include standard Klein or Hunstad techniques.

- Applying sterile conductive gel to the skin surface to reduce friction and improve electrical contact between external electrode and skin.

- Insertion of the RFAL cannula into the tissue, after adjusting the desired treatment depth into the tissue. Treatment should start in deeper planes moving up to more superficial planes while staying in the same thermal zone. The cannula movement should be slow, with 2-3 seconds for a back and forth cycle.

- Performing RFAL treatment with simultaneous aspiration.

- Treatment of each thermal zone should end when one of the following end points are reached:

- $\quad 6-12 \mathrm{~kJ}$ is deposited in the treatment zone. Higher $\mathrm{kJ}$ can be deposited in thicker fatty layers, such as the lower abdomen, and less kJ for thinner areas such as the epigastrium or neck

- The cut-off temperature is reached and maintained for a few minutes

- Skin erythema

- Final contouring of the area should be done without RF, with a focus on contouring and uniformity.

- $\quad$ Applying drains and suturing ports, if necessary.

- Applying compressing foams and garments; considered critical for proper healing and symmetrical tightening.

\subsection{Blood vessels coagulation}

The coagulation of blood vessels is a process naturally associated with a thermal treatment. The coagulation of vessels may have a positive effect in reducing the bruising and blood loss, however, it may present a safety concern as the termination of blood supply to the dermis can potentially cause skin necrosis.

The macro observation of the RFAL procedure allows the authors to conclude that hematocrit in the aspirating fat is lower during RFAL procedure compared to suction assisted lipoplasty (SAL). Observation of RFAL after an abdominoplasty shows no bleeding in the adipose fatty tissue from a $5 \mathrm{~mm}$ to $30 \mathrm{~mm}$ depth while flowing blood vessels are observed in sub-dermal area, illustrated in Figure 4.

The histological studies and observation of tissue sections in abdominoplasty patients pretreated with RFAL concludes that small vessels such as capillaries, venules and 
artherioles are coagulated during the treatment [Figure 5], while the majority of larger blood vessels are not damaged and continue to supply blood to the dermis. Observations show less bleeding in the adipose fatty tissue in a 5 to $30 \mathrm{~mm}$ depth, whereas bleeding is observed from blood vessels in the subdermal area. Bleeding of the dermis can be observed after the treatment and no skin necrosis is observed at the 6 months follow-up. [4]

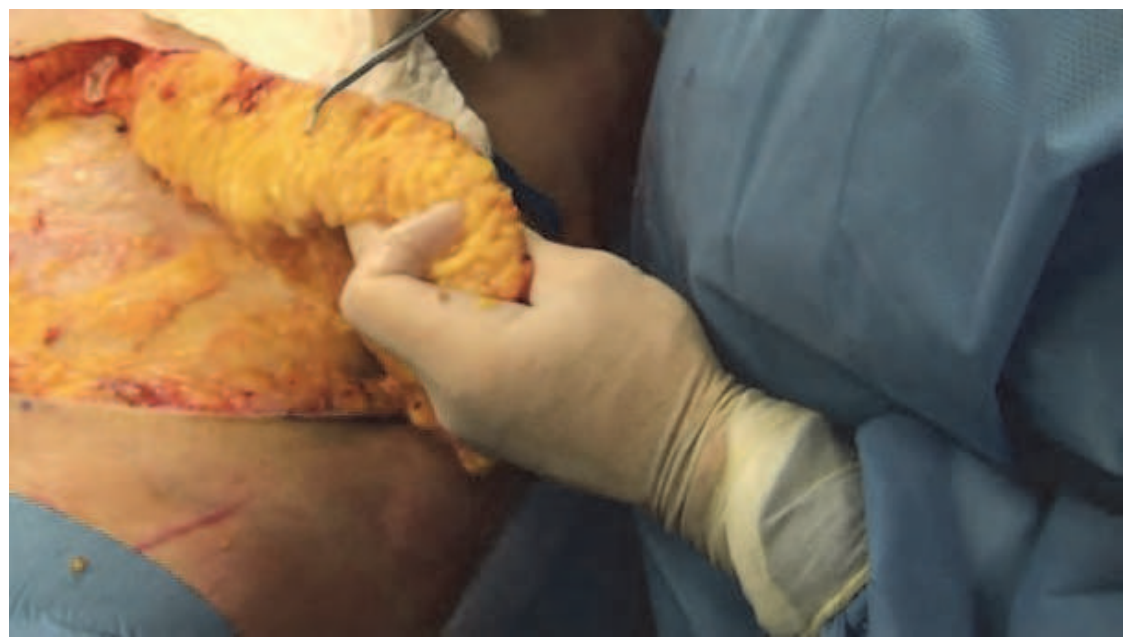

Fig. 4. Cross section of RFAL treated adipose tissue.

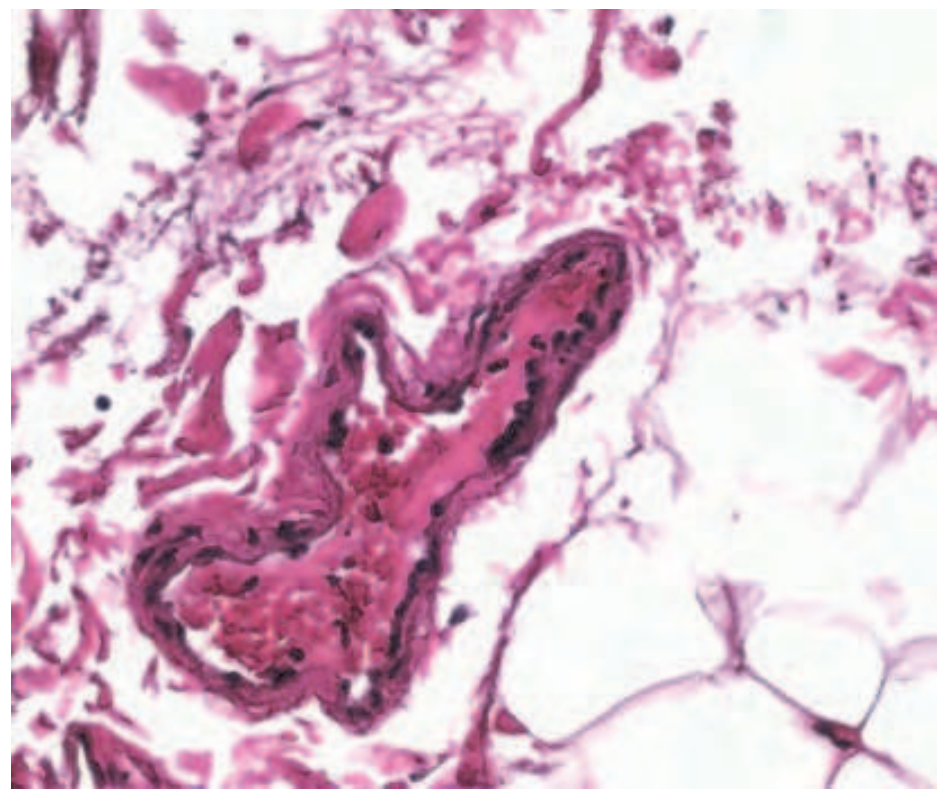

Fig. 5. Small coagulated blood vessel of the subcutaneous layer after RFAL . 


\subsection{Tissue tightening}

Skin appearance and tightening is a common concern during one's consideration for a liposuction procedure. Patients classified as obese, or with excessive skin, or compromised skin quality are typically excluded as liposuction candidates as fat removal can often leave behind excess lax skin causing their skin and body contour to appear worse. Skin laxity post liposuction can create patient dissatisfaction with the only solution being excisional surgery. Therefore, a liposuction method that can consistently contract the skin can address these patients who were previously excluded from treatment.

$\mathrm{RF}$ thermal induced contraction of collagen is well documented in medicine and is used in ophthalmology, orthopedic applications and treatment of varicose veins. Each type of collagen has an optimal contraction temperature that does not cause thermal destruction of fibroblasts, but induces a restructuring effect in collagen fibers. The reported range of temperatures causing collagen shrinkage varies from $60^{\circ} \mathrm{C}$ to $80^{\circ} \mathrm{C}$ [5-9]. At this temperature tissue contraction occurs immediately after tissue reaches the threshold temperature. The shrinkage of tissue is dramatic and can reach tens of percents of the heated tissue volume. This type of contraction is well studied in cornea [5], joints [6], cartilage [7, 8] and vascular tissue [9], but its application for the skin, sub-dermal and subcutaneous tissue tightening has not been as explored.

Non-invasive RF and lasers have been used for skin tightening effects since the mid 1990's [10-15]. Due to superficial thermal safety concerns, the skin surface temperature is maintained below $45^{\circ} \mathrm{C}$ and in order to increase the temperature in the deep dermis the skin is heated with RF or laser energy penetrating into the tissues deeper than $1.5 \mathrm{~mm}$, with simultaneous skin surface cooling. This sophisticated method of trans-epidermal, noninvasive RF thermal delivery provides a variable and controversial tightening effect, which is not usually apparent, if at all, until dermal remodeling occurs, a few months after the treatment.

Recently, thermal induced tissue tightening was expanded to minimally invasive treatments [11-15]. Using laser assisted liposuction or radio-frequency assisted liposuction, physicians have attempted to achieve reduction of subcutaneous tissue with simultaneous tissue contraction. DiBernardo reported $17 \%$ skin surface shrinkage measured at three months follow-up after LAL treatment [2]. RFAL technology provides a higher power and more efficient energy transfer than laser energy systems and thus, allows the treatment of larger volumes of the subcutaneous tissue with optimal thermal profiles, facilitating the significant tightening of the tissue. Recently introduced radio-frequency assisted liposuction and soft tissue contraction technology has shown tremendous promise for thermal contouring $[3,4$, 16-19].

When considering skin contraction, it is important to differentiate two-dimensional horizontal $x-y$ tightening of the skin surface from three-dimensional $x-y-z$ tissue tightening of the subcutaneous tissue, where the skin is also more firmly connected and adjacent to the deeper anatomical structures. If two-dimensional contraction is a function of collagen structure changes in dermis, the three-dimensional tissue tightening changes involve contraction of different types of collageneous tissue. We can separate the following types of collagen tissue in the subcutaneous space:

- Dermis - papillary and reticular.

- Fascia - relatively thick layer of connective tissue located between muscles and skin.

- Septal connective tissue - thin layers of connective tissue separating lobules of the fat and connecting dermis with fascia. 
- $\quad$ Reticular fibers - framework of single collagen fibers encasing fat cells.

\subsection{Ex-vivo tightening measurements}

An ex-vivo study [16] was conducted to measure subcutaneous collageneous tissue contraction with simultaneous monitoring of local tissue temperature, to determine the threshold temperature of the collagen shrinkage on different types of ex-vivo collageneus tissue samples.

Two types of collageneus tissue were studied for thermal induced contraction:

- Fascia

- Adipose tissue with septal and reticular connective tissue

The excised post abdominoplasty tissue samples were placed between the two BodyTite RF electrodes, where the small area, internal RF active electrodes (cannula) were placed in contact with the studied tissue and the other large area electrode was applied to the opposite side, or epidermal side, of the sample [Figure 6]. Two marks were placed at a distance of $1 \mathrm{~cm}$ from the active internal electrode to visualize tissue displacement.

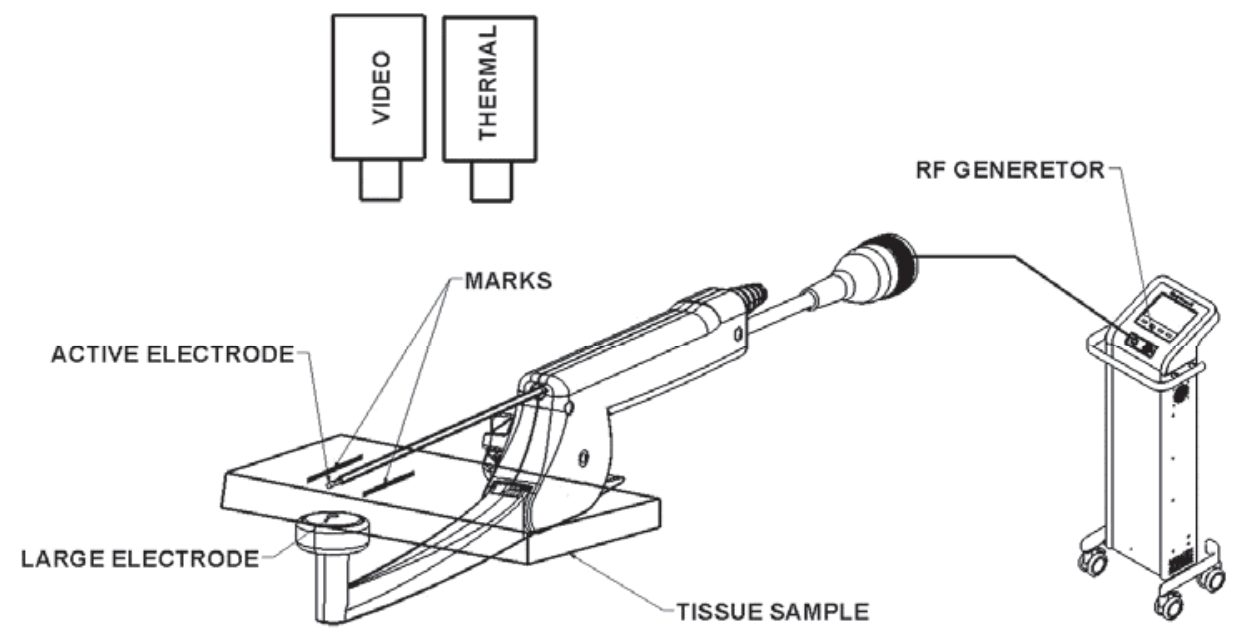

Fig. 6. Ex-vivo experiment set-up.

The delivered power was $75 \mathrm{~W}$, at $1 \mathrm{MHz}$ frequency; energy was delivered until evaporation of water from the adipocytes was observed.

Video and thermal cameras were used to monitor temperature change and tissue displacement during the treatment. The start of tissue displacement was correlated with tissue temperature to determine the contraction thermal threshold.

The adipose tissue with septal and reticular collagen behavior is shown in Figure 7.

The experiments showed that the marker movement (contraction) started within two seconds after the start of RF energy delivery. Adipose fibrous septal tissue coagulation and vaporization started to be observed at 13 seconds after initiating RF energy. Tissue contraction was not symmetrical as the displacement from one side was $8 \mathrm{~mm}$, and the other 
side presented an average displacement of $3 \mathrm{~mm}$. Non-symmetrical behavior can be explained by the non-uniform structure of the connective tissue and the non-symmetrical geometry of the studied tissue sample. The average marker migration and tissue contraction for the three experiments with adipose tissue was $6.5 \mathrm{~mm}$.

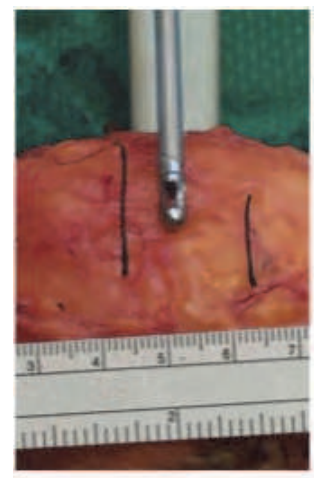

Before

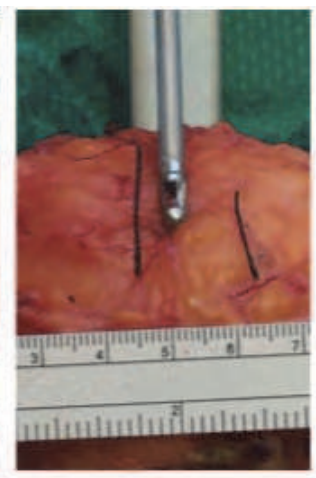

$4 \mathrm{sec}$

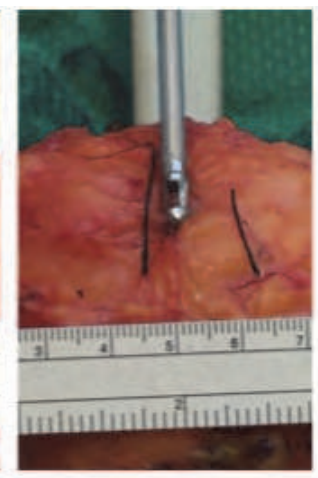

$6 \mathrm{sec}$

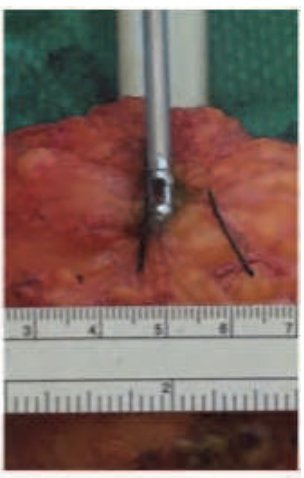

$13 \mathrm{sec}$

Fig. 7. Adipose-septal tissue behavior during RF energy delivery with time lapse.

Figure 8 shows thermal images of the same sample taken before the treatment, at the beginning of tissue displacement and at the end of the treatment showing the rise in thermal profile with time and onset of contraction.

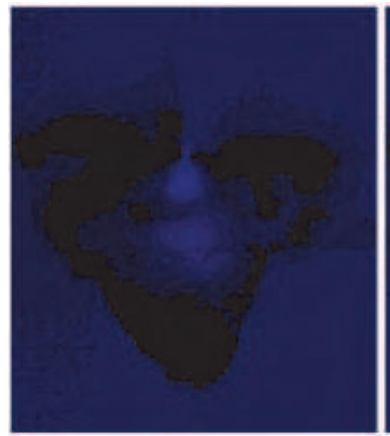

Before

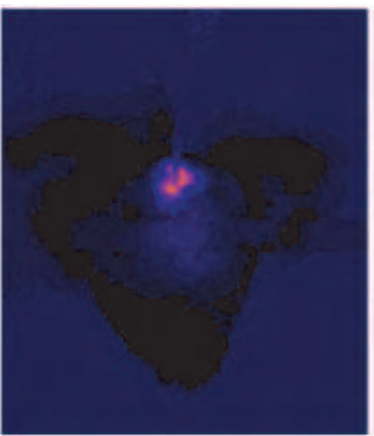

$2 \mathrm{sec}$
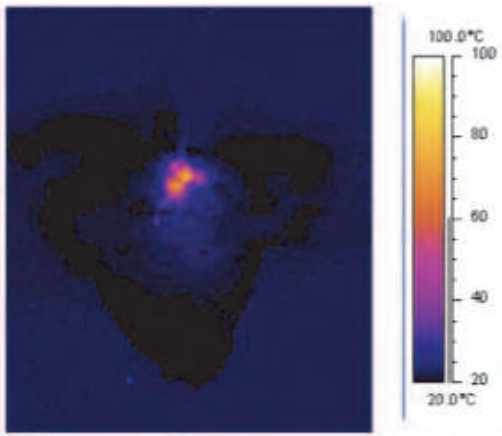

$13 \mathrm{sec}$

Fig. 8. Thermal images of adipose-septal tissue thermal behavior during RF energy delivery with time lapse.

For fascial tissue, contraction started when the maximal adipose tissue temperature near the active internal electrode reached $69.4^{\circ} \mathrm{C}$ and its response is illustrated in Figure 9.

The displacement of the markers and tissue contraction in fascia were significantly less than in adipose tissue. Average movement was $2.75 \mathrm{~mm}$, or approximately 2.5 times less than the mark migration and tissue contraction observed in adipose tissue.

The marker migration and medial contraction started after $3.5 \mathrm{sec}$ and maximal temperature near the active electrode at this moment was $61.5^{\circ} \mathrm{C}$. 


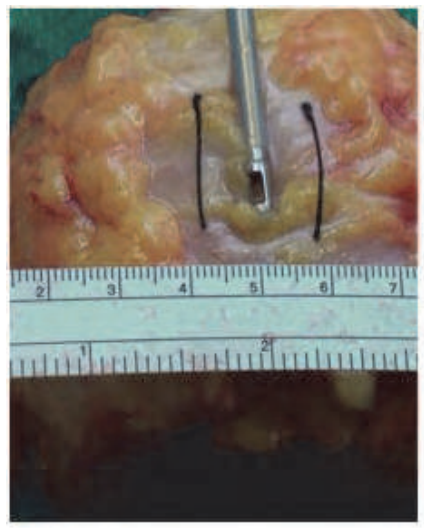

Before

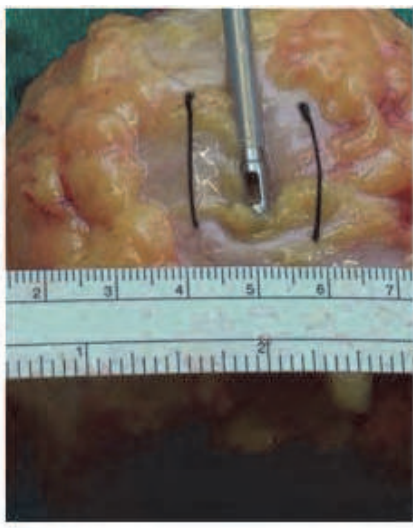

$1 \mathrm{sec}$

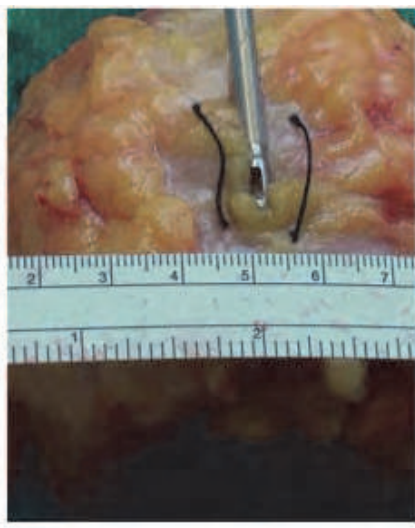

$15 \mathrm{sec}$

Fig. 9. Fascia contraction behavior during RF energy delivery with time lapse.

Table 1 summarizes the results on subcutaneous tissue contraction.

\begin{tabular}{|c|c|c|}
\hline & Fascia & Septa/Adipose Tissue \\
\hline Average Displacement, $\mathrm{mm}$ & 2.75 & 6.5 \\
\hline Threshold Temperature, ${ }^{\circ} \mathrm{C}$ & 61.5 & 69.4 \\
\hline
\end{tabular}

Table 1. Average displacement and contraction threshold temperature.

Results show the strongest contraction response in adipose tissue containing septal connective tissue and reticular collagen fibers encasing fat cells. Fascia and septa can be heated to these high, optimal contraction temperatures, but it can be done only in an minimally invasive transcutaneous manner that deposits the thermal RF energy directly into the adipose tissue and sub-dermal space, thus avoiding heating the epidermal surfaces.

The contraction temperatures of collagen in the ex-vivo study were in the same range reported for other collageneous tissues. Tissue contraction was observed in the area with diameter of $2 \mathrm{~cm}$, which corresponds to a spherical contraction volume of $4.2 \mathrm{~cm}^{3}$. Knowing the tissue volume and deposited energy before the start of contraction, one can estimate the energy density required for each cubic centimeter of treated tissue to reach tissue contraction effects. It can be calculated that for $1 \mathrm{~L}$ of adipose tissue, up to $48.3 \mathrm{~kJ}$ is required to start to see immediate and significant collagen contraction. These tissue energy calculations for initiation of adipose contraction are consistent with empirical data obtained with LAL treatment where energy from $50 \mathrm{~kJ}$ up to $100 \mathrm{~kJ}$ per liter is recommended for the treatment of the abdominal area.

The ex-vivo experiments produced different degrees of contraction for septal and dermal tissues that emphasizes the balance between these processes for optimal aesthetic results. Lower two-dimensional contraction of the skin and significant three-dimensional contraction of sub-dermal adipose connective tissue may cause wrinkling of the skin surface for high volume liposuction patients.

In-vivo clinical monitoring of temperature, both in the adipose tissue and the epidermal surface, should allow the physician to more accurately predict the thermal treatment times and reduce the risk of thermal injuries. 


\subsection{In-vivo evaluation with radio-frequency assisted liposuction}

An in-vivo study [16] enrolled 24 patients, 22 female and 2 male patients, who underwent RFAL to the abdomen and hips. The average age was 39.7 years old (range 19-52 years) with an average pre-operative weight of $71 \mathrm{~kg}$. The selected patients were typical candidates for a liposuction procedure. All patients were active with no significant medical diseases. 15 of 24 patients had a normal body mass index (BMI) $(<25)$, while 9 of 24 patients were moderately overweight (BMI 25-30) and 3 patients were obese (BMI $>30$ but $<32$ ).

The RF power, in the range of 40 to $75 \mathrm{~W}$ was used for uniform heating throughout a thick subcutaneous flap. The average total energy, $72 \mathrm{~kJ}$, was delivered to the abdominal area. The temperature around the tip of cannula reached $70-80^{\circ} \mathrm{C}$. The skin temperature was monitored and energy cut-off levels were in the range of $38-42^{\circ} \mathrm{C}$, which was maintained for 1-3 minutes. The strong and sustained tissue heating during the procedure resulted in a thermal stimulation of the sub-dermal layer, the entire matrix of adipose tissue and the vertical and oblique fibrous septa, eliciting a powerful three-dimensional retraction and contraction of the entire soft tissue envelope.

All patients had their treatment area infiltrated with tumescent anesthesia prior to RFAL. Tumescent anesthesia is critical in the technique as the RF current travels through tissue most efficiently in a salinated environment.

The objective of this in-vivo study was to correlate treated soft tissue contraction results with procedure and patient variables including amount of deposed RF energy, body mass index, and amount of aspirated fat.

A zone measuring approximately $15 \times 10 \mathrm{~cm}\left(150 \mathrm{~cm}^{2}\right)$ can be heated to a critical target temperature within 3-8 minutes, depending on the thickness of the treated fat layer and then safely maintaining uniform volumetric heating to reach uniform temperature distribution over the entire treated volume.

All patients from the study were followed at 6 weeks, 3 months and 6 months. In order to measure linear two-dimensional contraction, the distance between two fixed points was measured preoperatively and then at the 6 months postoperative visits. Distances between incision ports and natural "fixed" anatomical registration points, such as moles or the umbilicus were measured before the treatment, after the treatment and at 3 and 6 months follow-up visits. The linear contraction was measured as the relative change of distance between two points over the curved surface of the body. Distances were measured using a flexible ruler applied over the skin surface [Figure 10]. For the abdominal area, at least 3 measurements were taken between 3 different points and an average linear contraction was calculated.

All RFAL patients demonstrated some level of contraction. From $8 \%$ to $15 \%$ linear tightening was observed at the end of the surgery on the operating table, which further increased dramatically during first week when most of the swelling was reduced. The linear and area contraction process continued over the subsequent weeks and maximum contraction was noted at the last follow-up visit 24 weeks after the treatment.

Linear contraction observed at 6 months follow-up were much more significant than reported with any other technology, and varied from $12.7 \%$ up to $47 \%$ depending on the patient and treatment variables. It is important to note that soft tissue area contraction can be estimated as the square of the linear contraction and represents much higher numbers.

The measured linear contraction was then correlated using three parameters:

- Aspirated volume that was varied in the range of $0.5 \mathrm{~L}$ to $3.4 \mathrm{~L}$ with average volume of 2.0L. 

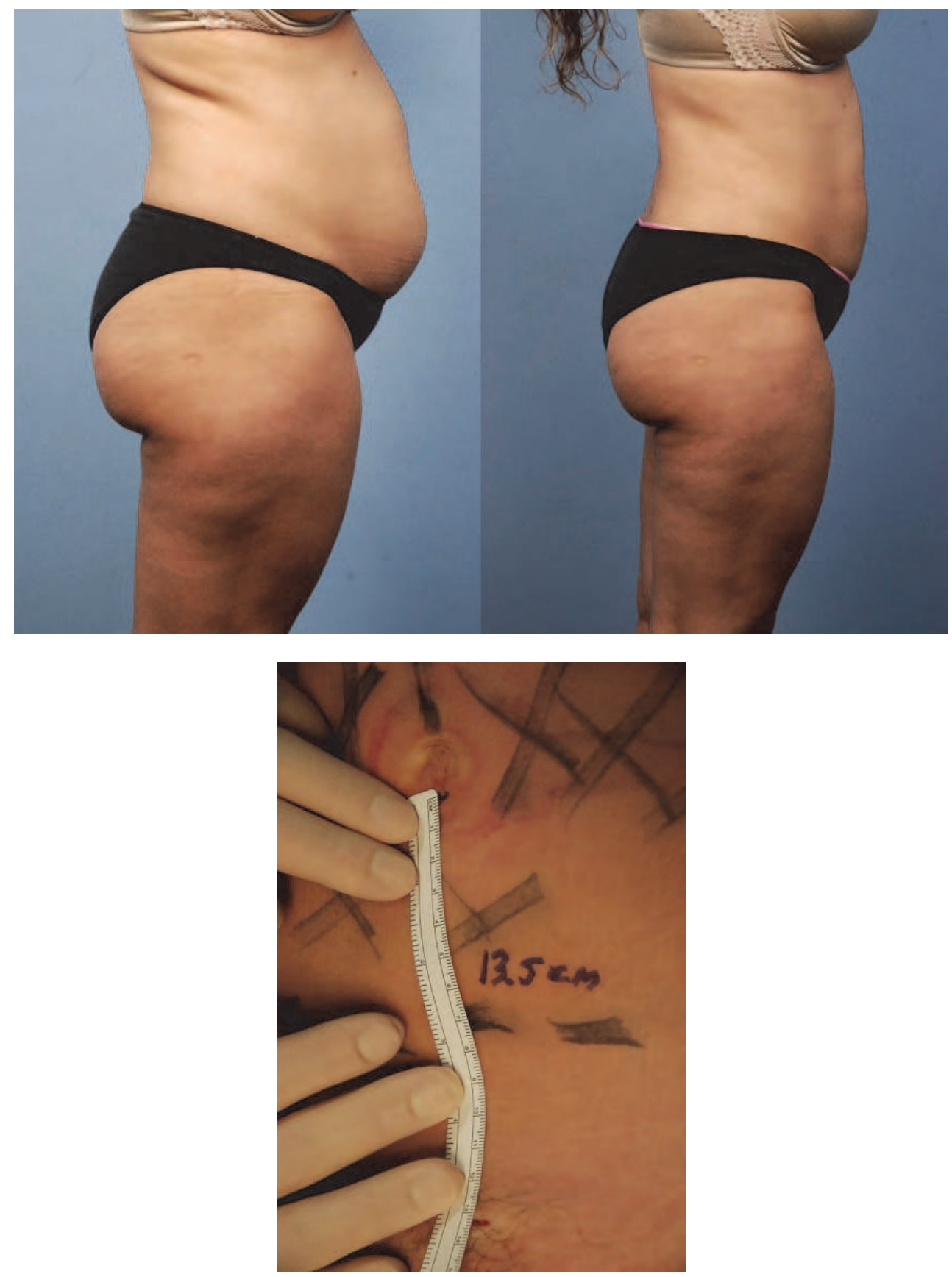

Fig. 10. Before and After RFAL and intra-operative two point linear contraction registration points from pubic RFAL incision point to the lower point of the umbilicus. 
- $\quad$ BMI of the patients that varied from 20.8 to 31.7 with an average index of 25.7.

- Deposited RF energy that was varied from $60 \mathrm{~kJ}$ to $96 \mathrm{~kJ}$ per abdominal area with an average number of $72 \mathrm{~kJ}$.

For statistical analysis of the correlation between the measured variables and linear contraction, the coefficients were calculated. The closer the coefficient to the 1 , the higher the linear correlation is between the measured variable and tissue contraction.

Analysis shows no or very weak correlation between aspirated volume and linear skin contraction. The Pearson coefficient is about 0.22. Figure 11 shows the correlation between these values, with a random distribution.

The Pearson coefficient for correlation between contraction and patient BMI is much higher and equals 0.64 . It is easy to naturally come to the conclusion that a patient with a larger volume of adipose tissue would have more tissue available to undergo contraction thus providing a much stronger connection between these parameters [Figure 12].

The highest correlation (0.86) was obtained between deposed RF energy and skin contraction. Figure 13 shows the measured results that almost has a linear function between these two parameters. The more energy deposited, the more linear contraction that was observed.

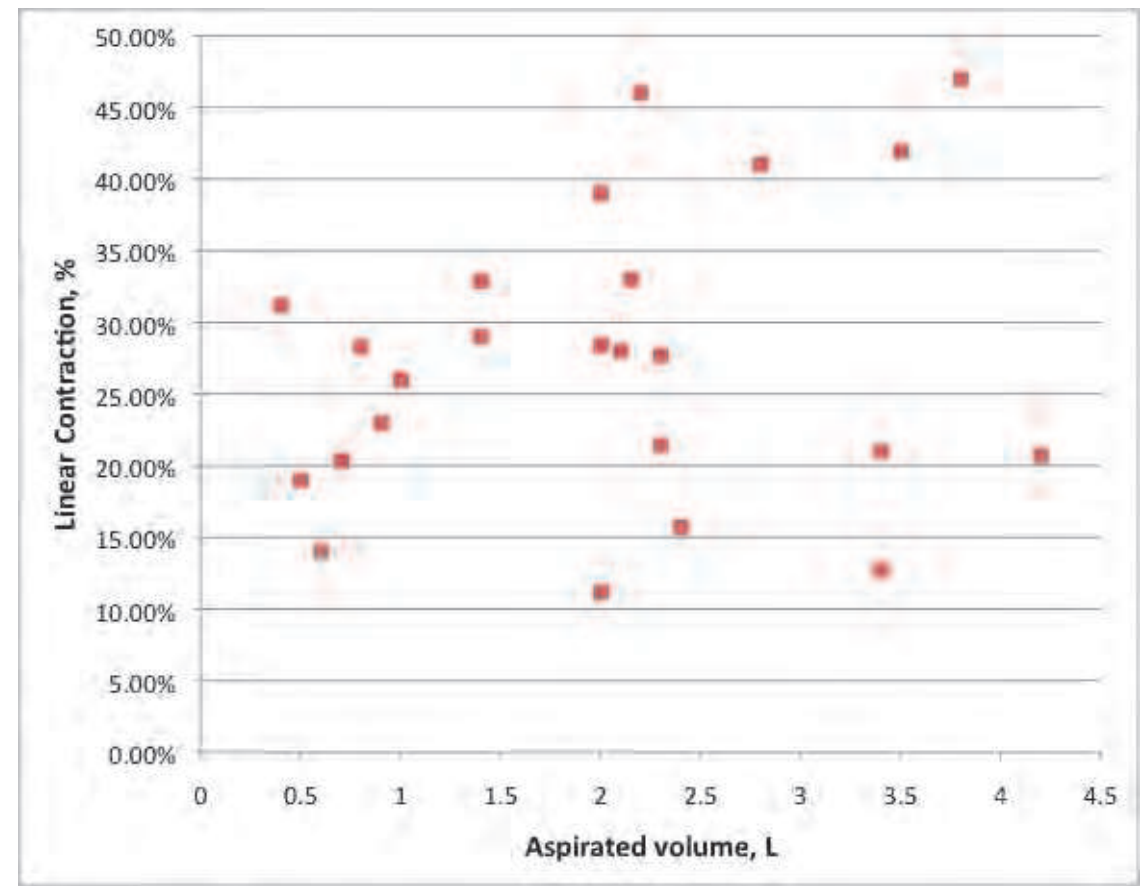

Fig. 11. Correlation between aspirated volume and linear contraction. 


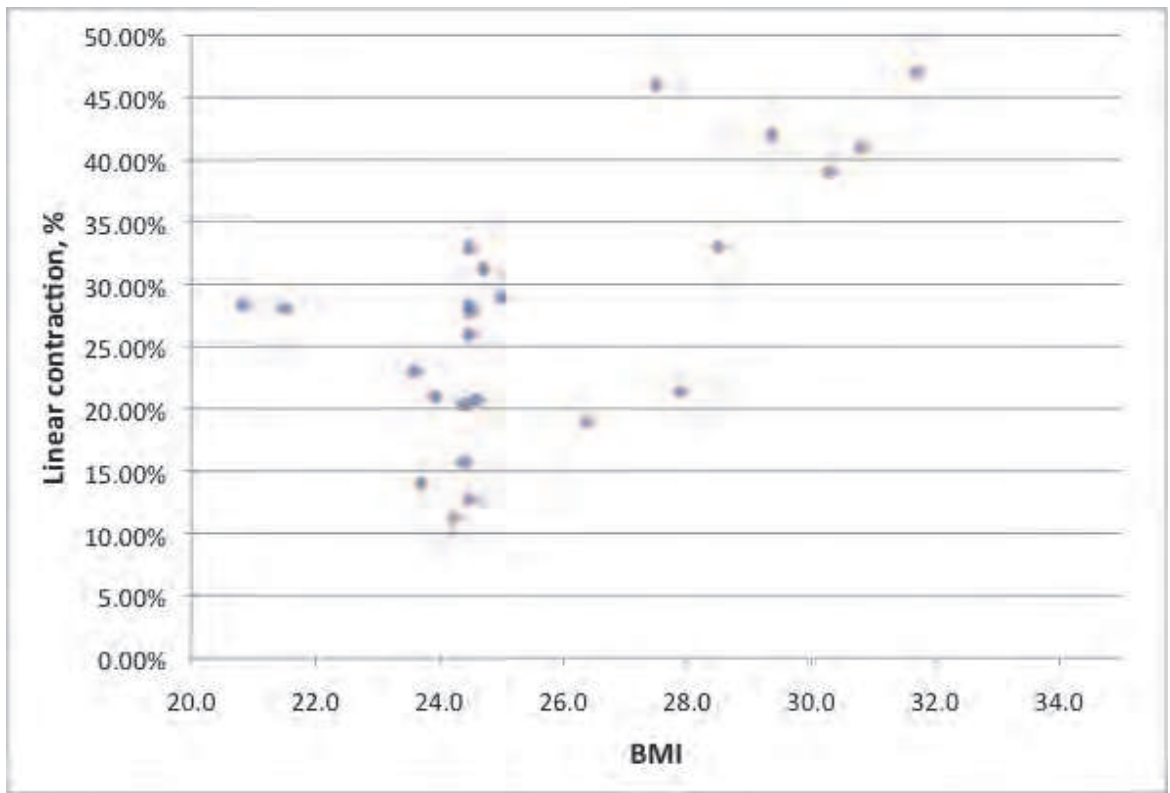

Fig. 12. Correlation between BMI and linear contraction.

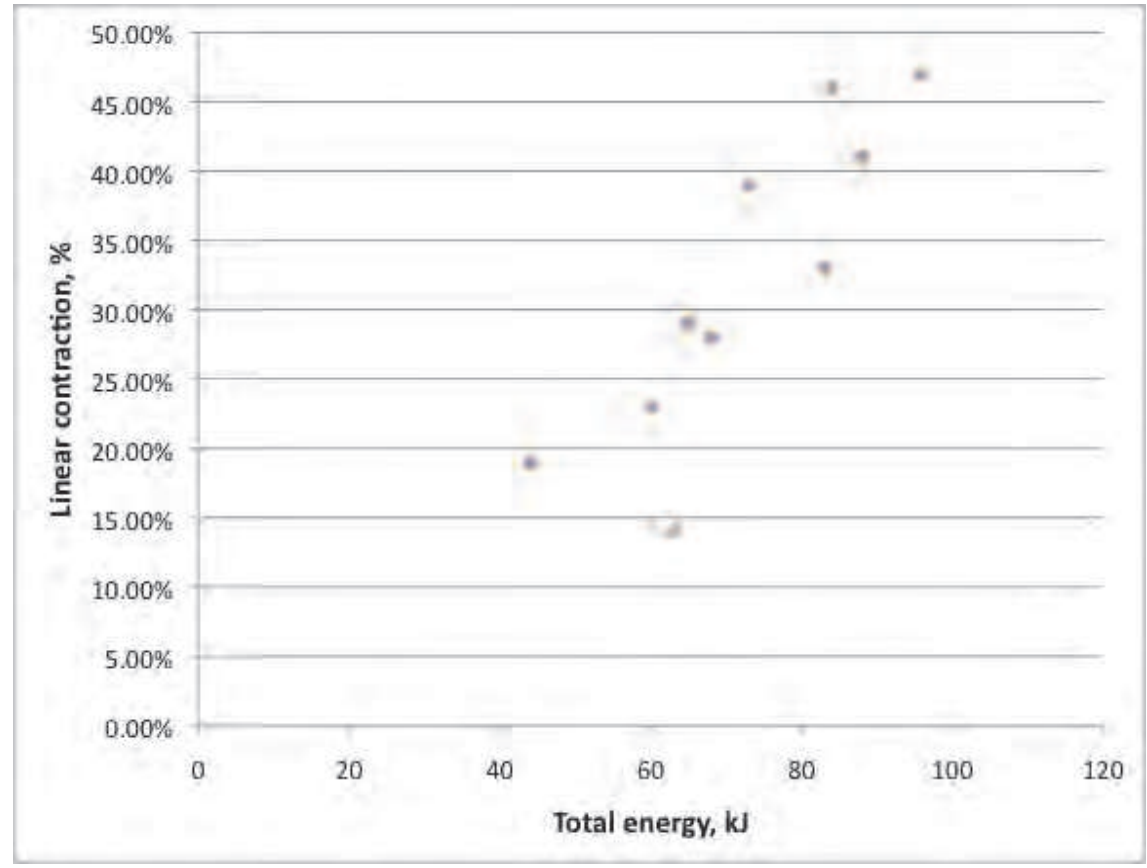

Fig. 13. Correlation between total energy and linear contraction. 
In spite of improved contraction obtained at higher energies, the amount of energy during the treatment should be measured and controlled to avoid negative side effects such as seromas and skin burns while still achieving optimal linear and area contraction.

Features of an ideal liposuction procedure would include reduced ecchymosis, pain, and edema from pre-aspiration coagulation of adipose and vascular tissue, followed by less forceful and traumatic extraction forces, as well as a significant soft tissue contraction when host tissue elasticity is compromised. Thermal based lipoplasty appears to hold this potential.

In the present study based on volumetric heating we reached an average local linear contraction of $31 \%$. This is statistically significantly higher than that reported with other energy emitting liposuction technologies. Overall area contraction was much higher than the linear contraction. These in-vivo results confirm the proposed mechanism of RF based tissue tightening and recruitment of the vertical and oblique fibrous adipose matrix.

About $30 \%$ of patients noted minor weight loss, however, it is premature to correlate it with treatment procedure. Further studies are recommended to explore this relationship.

The study reported one seroma, which was treated with closed serial aspiration. Seroma is not a rare side effect for energy-assisted liposuction, especially for high volume treatment and may necessitate a lower threshold for closed drainage systems in selected patients.

The RFAL is a versatile procedure and provides advantages for a myriad of treatment concerns. Similar to UAL, RFAL has the ability to work through more fibrotic tissue common in the male chest [Figure 14] or characteristic of secondary liposuction cases. In addition, its ability to offer the highest contraction rate of all energy treatments allows RFAL to be considered for large volume patients [Figure 15] or patients with compromised skin laxity. The varied number of hand piece configurations also permits RFAL to be used for fat aspiration in combination with tightening, such as the body and breasts [Figure 16], or pure skin tightening procedures, where fat removal is a secondary concern, as desired in areas as arms, neck and face treatments [Figure 17].
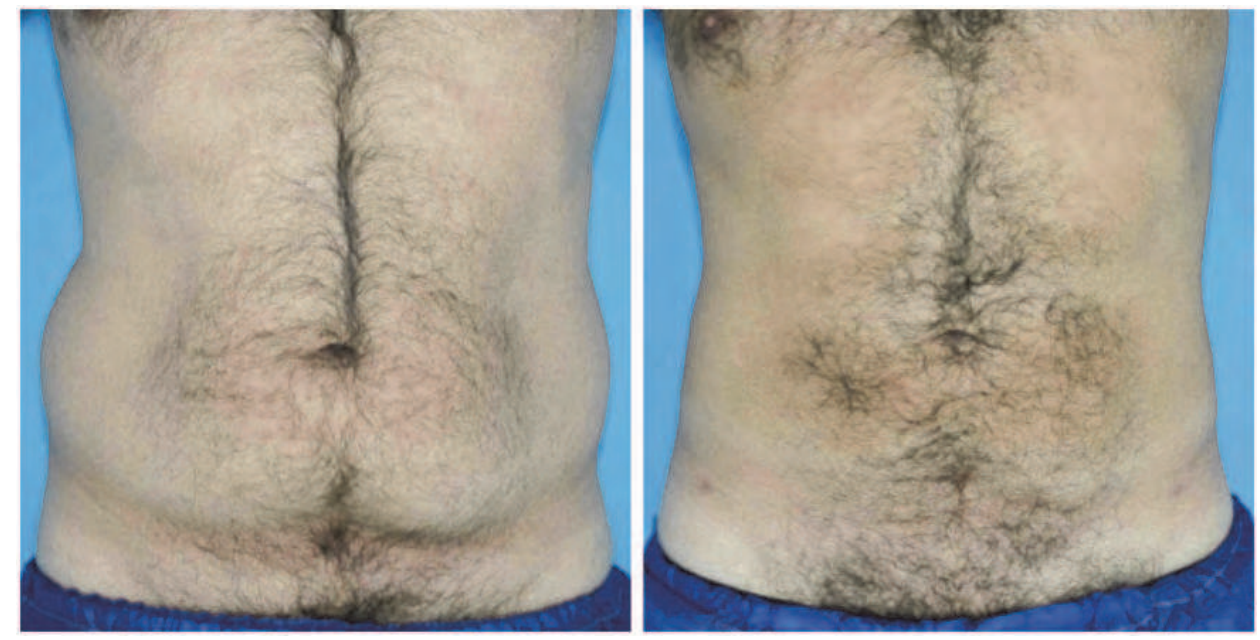

Fig. 14. Before and 3 months post treatment of a male patient with $13.6 \%$ reduction in waist circumference. 


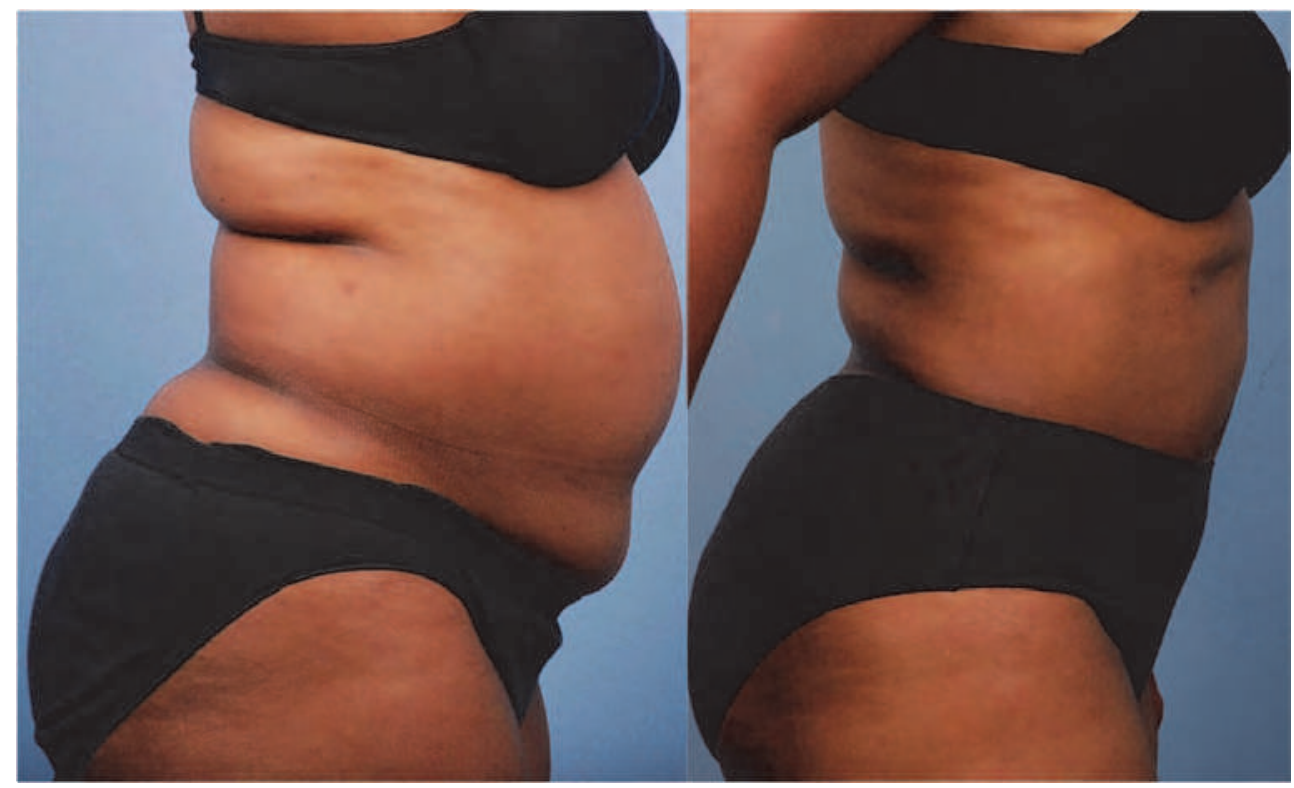

Fig. 15. Before and 6 months post treatment of a large volume female patient.

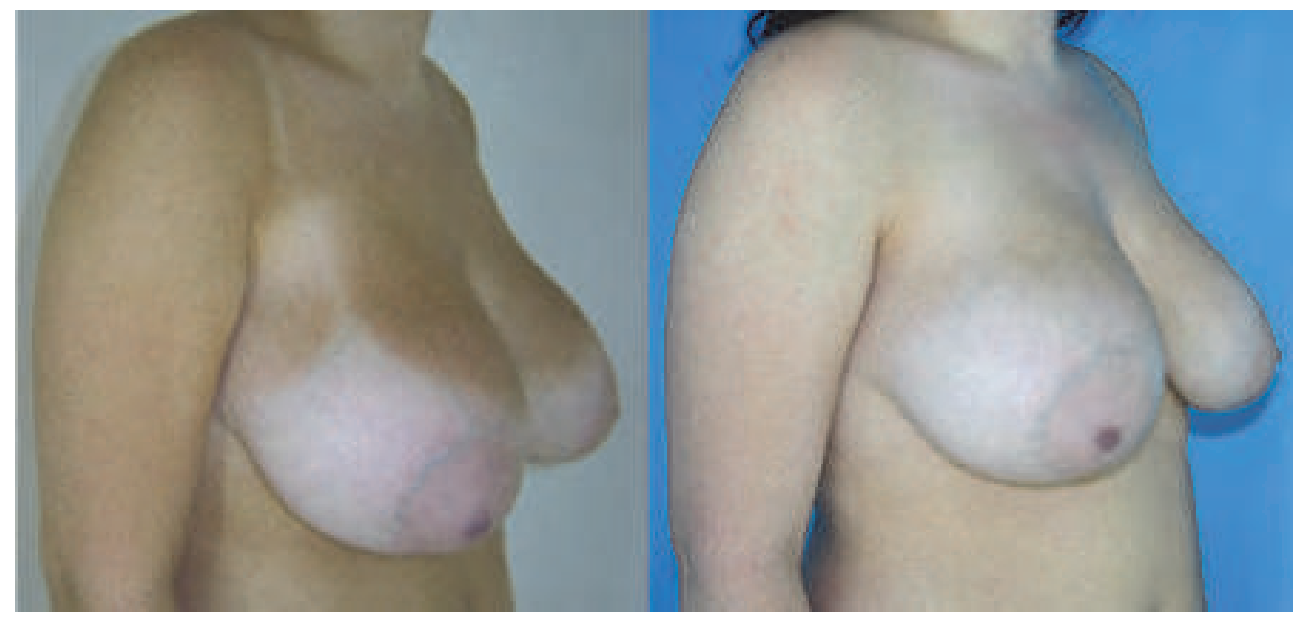

Fig. 16. Before and 4 months post treatment with $2500 \mathrm{cc}$ removed to provide a breast lift. 


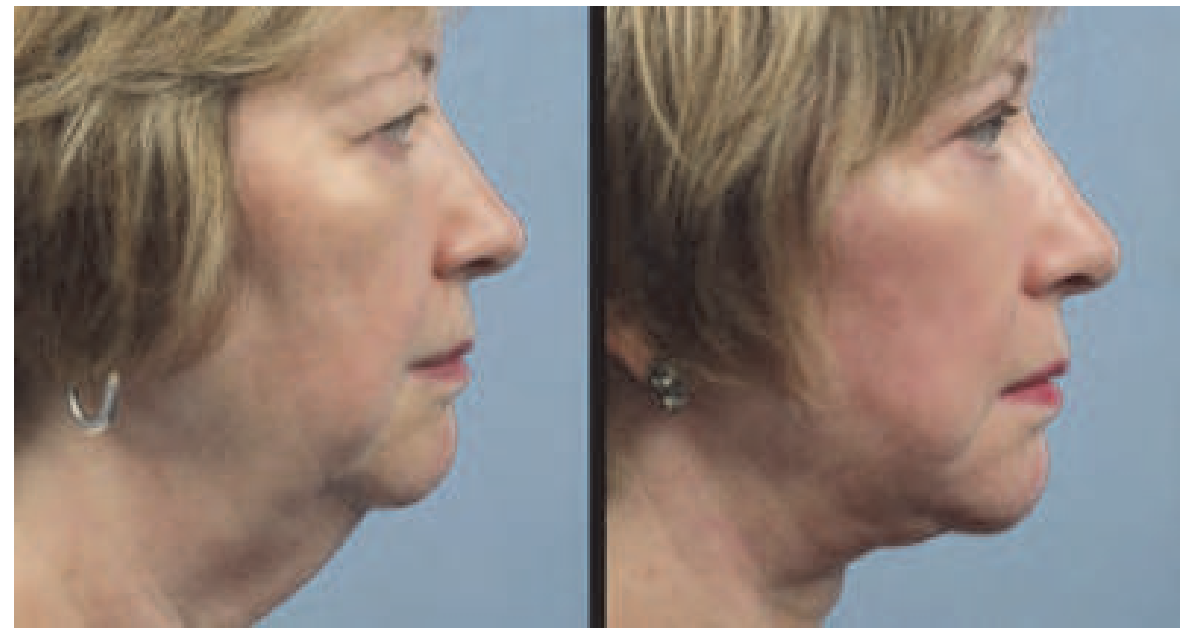

Fig. 17. Before and 3 months post treatment of the neck and face providing tightening and contour.

\subsection{Histologic and MRI studies}

Pre and post-operative photography, weight and circumferential reduction data were obtained on all patients.

The skin histologies taken from biopsies immediately following the RFAL treatment show a canal created by the cannula, which thermally destructed adipocytes around the canal [Figure 18].

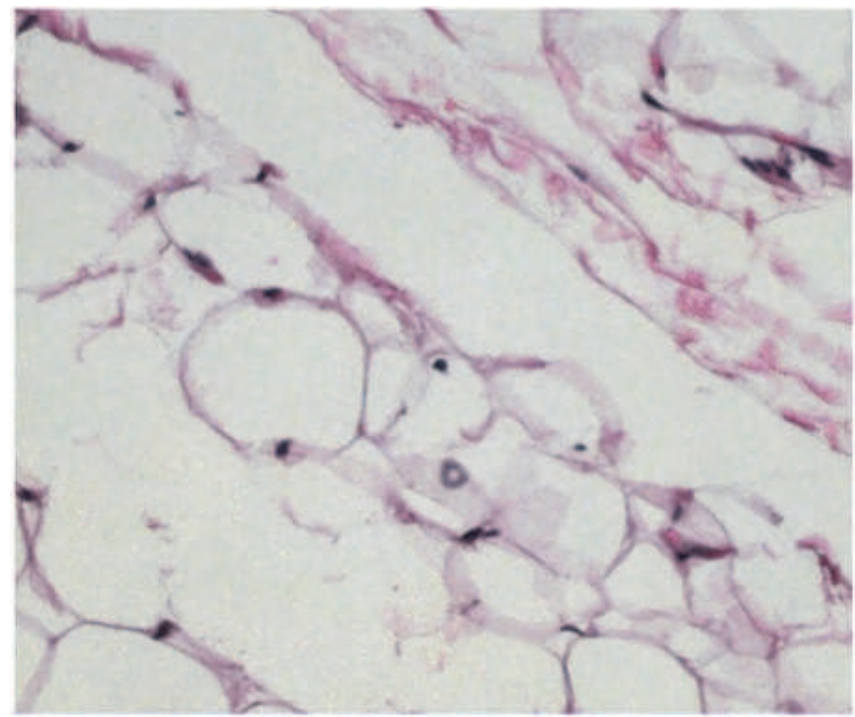

Fig. 18. After RFAL, channels in the fat tissue are observed and surrounded by disrupted fat cells. 
Skin biopsies taken from an RFAL study patient at 12 months, show normal dermal architecture, with healthy collagen and elastin fibers in the deep reticular dermis with no evidence of scar tissue or abnormal collagen fibers [Figures 19, 20].

A magnetic resonance imaging study of five patients before and three months after RFAL [18] showed a reduction in the thickness of adipose tissue in treated area and an increase of collageneus tissue in subcutaneous fat [Figure 21]. Signals of remaining edema could be observed 90 days after treatment, signaling the continued persistence of the reparatory process.

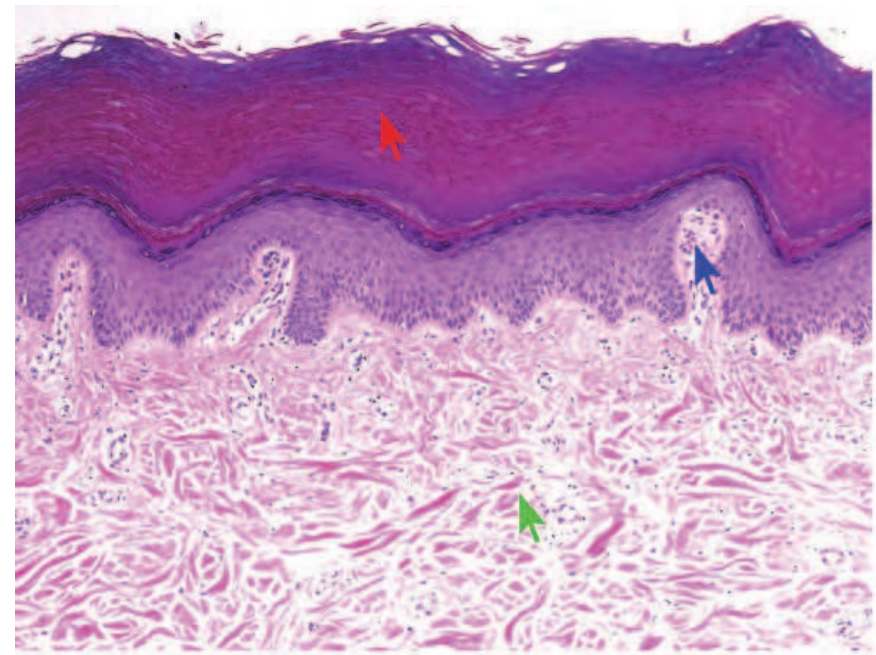

Stratum corneum is thick

\section{Papillary dermis}

\section{Reticular dermis}

Fig. 19. Normal skin histology 12 months following optimal RFAL thermal endpoint.

\section{Patient comfort and safety}

Data and feedback compiled from a few hundred RFAL patients illustrate that the treatment is safe for small and large areas [3, 4, 16-19]. Most patients were able to return to a regular routine a few days following the treatment. In addition, for single or small zone procedures, the treatment can be performed under local anesthesia thereby reducing the risks related to general anesthesia. Most patients were drawn to RFAL as there was a reduction of downtime caused by bruising or pain.

The main safety precautions are:

- $\quad$ Limit deposited RF energy per zone of $150 \mathrm{~cm}^{2}$ by $6-8 \mathrm{~kJ}$ for thin skin less than $2.5 \mathrm{~cm}$ thickness and by $12 \mathrm{~kJ}$ per thick fat layer.

- Observe skin reaction during treatment, the appearance of erythema indicates a strong effect for tumescent infiltrated tissue and should be considered an end point. 
- In many cases skin temperature up to $36-38^{\circ} \mathrm{C}$ is enough to get good results, especially for thick skin layers.

- Avoid the return of the cannula to the same point. This can cause focal over-heating and can be prevented by moving the hand piece in a zig-zag pattern.

- Move the cannula slowly to control its position and maintain its thermal effect.

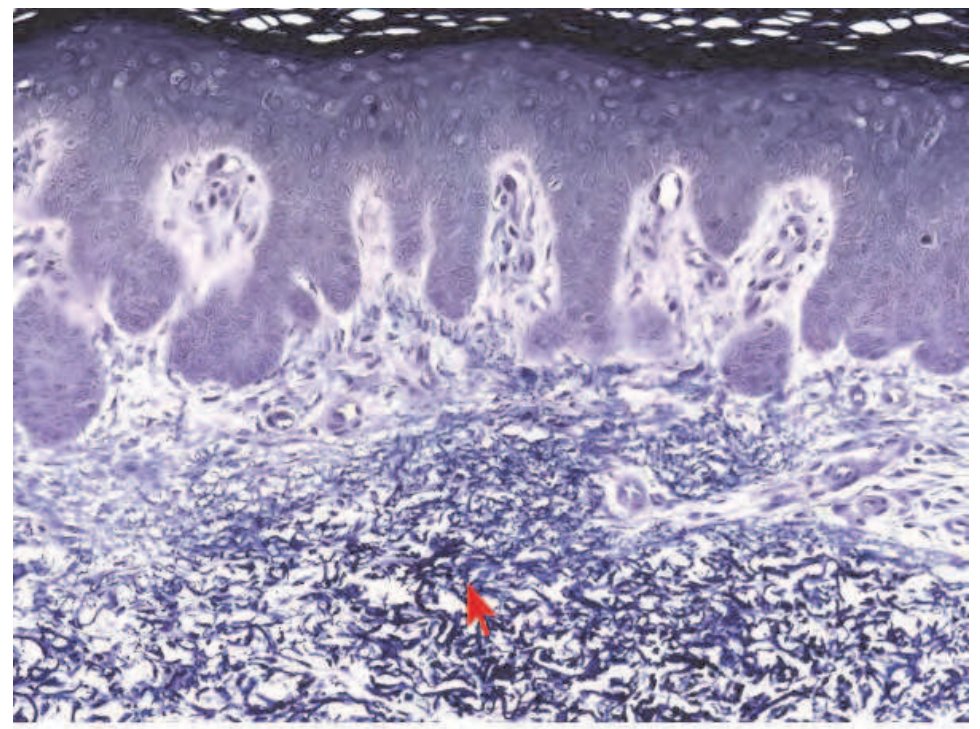

\section{Elastic fibers}

Fig. 20. The same RFAL patient as in Figure 12 with $43 \%$ contraction and normal elastic fiber content.
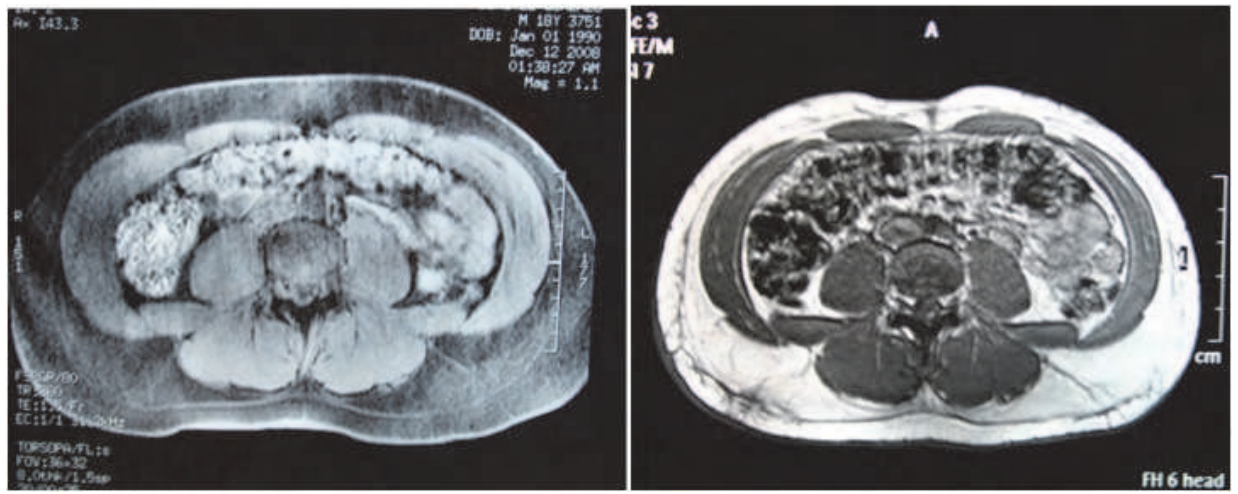

Fig. 21. Magnetic resonance imaging of the abdomen before (left) and 3 months after (right) RFAL, showing significant reduction of the abdominal fat thickness and mild edema. Note the indentation of the mid-abdominal line at 3-month follow-up, which was absent prior to the procedure. 


\section{Acceptance by physicians}

Acceptance by physicians can be quite high as there are only a few changes to the standard liposuction technique, these include reducing the speed of cannula movement and ensuring the cannula does not return to the same return point.

A comparison of RFAL aspiration speed with a standard Mercedes liposuction cannula, each with the same diameter, conducted on a split body treatment demonstrated a $17 \%$ higher aspiration speed with RFAL compared to a regular cannula. Measurements of aspirated tissue volume after 20 minutes of treatment showed $490 \mathrm{ml}$ fat extracted with RFAL, compared with $420 \mathrm{ml}$ with the regular cannula. The increased speed of RFAL over standard liposuction is likely the result of the lower viscosity and increased flow following Poiseuille's law [3]. However, in a true treatment setting physicians using RFAL may see an increase in the treatment time by about $10-20 \%$ depending on number of treatment areas. Overall, the majority of energy based liposuction techniques require an increase in treatment time and thermal assisted procedures require more attention from physician to control in parallel thermal and contouring processes.

The skin tightening benefits demonstrated through the treatment results, is an advantage that standard liposuction and other thermal treatments are unable to reproduce. Often these results can only be provided with more extensive excisional surgeries. The ability of RFAL to provide the patient an alternative to abdominoplasty or brachioplasty provides the surgeon a highly sought after competitive advantage.

\section{Conclusion}

The main advantage of RFAL is consistent and substantial 3-dimensional tissue contraction resulting from the heating of subcutaneous tissue without significant increase in the length of the procedure. The tightening of the tissue with RFAL broadens the physicians ability to treat a more diverse population who may require stronger contraction in addition to fat reduction. It is the experience of the authors that RFAL provides a safe procedure with obvious tightening benefits for the aesthetic medical market.

There is potential of the RFAL technology in following specific cases where skin contraction is critical:

- Treatment of overweight patients

- Treatment of patients after weight loss

- Treatment of areas with saggy skin and low fat content such as the upper arms, neck and face

- High potential in the treatment of cellulite

While RFAL technology does not solve all the above mentioned problems, it greatly expands the horizon of liposuction technology to a broader patient demographic.

\section{References}

[1] Scuderi N, Tenna S, Spalvieri C, De Gado F. Power-assisted lipoplasty versus traditional suction-assisted lipoplasty: Comparative evaluation and analysis of output powerassisted lipoplasty versus traditional suction-assisted lipoplasty: Comparative evaluation and analysis of output. Aesth Plast Surg. 2005;29:49-52.

[2] DiBernardo B. ASAPS, The Best of Hot Topics - Lipo-Transfer and SmartLipo, May 6 2008. 
[3] Mulholland RS. An in-depth examination of radiofrequency-assisted liposuction (RFAL). J Cosmet Surg Med. 2009, September;4(3):14-19.

[4] Paul M, Mulholland RS. A new approach for adipose tissue treatment and body contouring using radiofrequency-assisted liposuction. Aesth Plast Surg. 2009;33(5):687-694.

[5] Asbell P, Maloney RK, Davidorf J, Hersh P, McDonald M, Manche E. Conductive Keratoplasty for the correction of hyperopia, Tr. Am. Ophth. Soc. 2001; 99:79-87.

[6] Obrzut SL, Hecht P, Hayashi K, Fanton GS, Thabit G III, Markel MD. Effect of radiofrequency on the length and temperature properties of the glenohumeral joint capsule. Journal Arthroscopy Rel Surg. 1998, May-Jun;14(4):395-400.

[7] Lu Y, Edwards R III, Cole BJ, Markel MD. Thermal chondroplasty with radiofrequency energy, an in vitro comparison of bipolar and monopolar radiofrequency devices. American Journal of Sports Medicine. 2001, Jan-Feb;29(1):42-9.

[8] Lu Y, Edwards R III, Kalscheur VL, Nino S, Cole BJ, Markel MD. Effect of bipolar radiofrequency energy on human articular cartilage: Comparison of confocal laser microscopy and light microscopy. Journal Arthroscopy Rel Surg. 2001, Feb;17(2):117-23.

[9] Theodore H. Teruya, MD, Jeffrey L. Ballard, MD, New approaches for the treatment of varicose veins, Surg Clin N Am. 2004;84:1397-1417.

[10] Mayoral, Flor A. Skin tightening with a combined unipolar and bipolar radiofrequency device.(CASE REPORTS), Cosmet Laser Ther. 2005;7:11-15.

[11] Fatemi A, Weiss MA, Weiss RA. Short-term histologic effects of nonablative resurfacing: results with a dynamically cooled millisecond-domain $1320 \mathrm{~nm}$ Nd:YAG laser. Dermatol Surg. 2002, Feb;28(2):172-6.

[12] Mayoral FA. Skin tightening with a combined unipolar and bipolar radiofrequency device, J. of Dugs in Derm. 2007, Feb;6(2):212-215.

[13] Doshi SN, Alster TS. Combination radiofrequency and diode laser for treatment of facial rhytides and skin laxity. Effect of controlled volumetric tissue heating with radiofrequency on cellulite and the subcutaneous tissue of the buttocks and thighs. Journal Drugs Dermatol. 2006;5:714-722.

[14] Zelickson B, Kist D, Bernstein E, et al. Histological and ultrastructural evaluation of the effects of a radiofrequency-based nonablative dermal remodeling device: a pilot study. Arch Dermatol. 2004; 140:204-209.

[15] Hsu T, Kaminer M. The use of nonablative radiofrequency technology to tighten the lower face and neck. Semin Cutan Med Surg. 2003;22:115-123.

[16] Paul M, Blugerman, G., Kreindel, M., Mulholland RS. Three-Dimensional Radiofrequency Tissue Tightening: A Proposed Mechanism and Applications for Body Contouring. Aesth Plast Surg. 2010, Sept. [Epub ahead of print]

[17] Sandhofer M, Schauer P, Blugerman G, Schavelzon D, Paul MD. Sicherheits- und Machbarkeitsstudie einer neuen radiofrequenzassistierten Fettabsaugungstechnik. Journal Fur Aethetische Chirurgie. 2010.

[18] Blugerman G, Schavelzon D, Paul MD. A safety and feasibility study of a novel radiofrequency assisted liposuction technology. Plast Reconstr Surg. 2010;125(3):998-1006.

[19] Paul M, Mulholland RS. A New Approach for Adipose Tissue Treatment and Body Contouring Using Radiofrequency-Assisted Liposuction. Aesth Plast Surg. 2009;33: 5 687-694. 


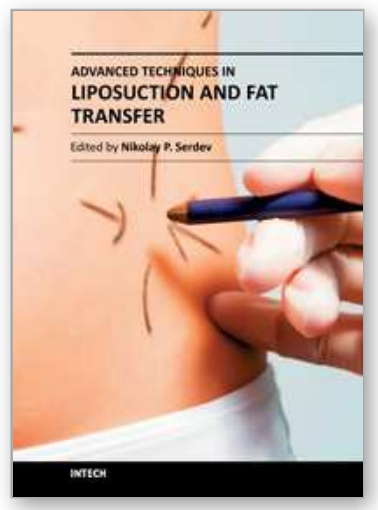

\author{
Advanced Techniques in Liposuction and Fat Transfer \\ Edited by Prof. Nlkolay Serdev
}

ISBN 978-953-307-668-3

Hard cover, 230 pages

Publisher InTech

Published online 12, September, 2011

Published in print edition September, 2011

Liposuction is the first cosmetic procedure to change beutification surgery from open extensive excision surgery into a more atraumatic closed one. It gave rise to the modern understanding of minimally scarring and minimally invasive surgery and changed the understanding and preferences of both patients and doctors. It also became the most common procedure in cosmetic surgery world-wide, practiced by an increased number of physicians from various specialties. The techniques of fat grafting, closely bound with liposuction, have found widespread application and fat stem cells seem to be changing the future of many areas in medicine. Turning the pages, the reader will find a lot of information about advances, tips and tricks, as well as important milestones in the development of the different methods available, such as classic, power, ultrasound, laser and radio-frequency assisted liposuction etc. Most useful anesthesia techniques are described and discussed, and guidelines have been established for medical indications. Special attention is paid to good patient selection, complications and risks.

\title{
How to reference
}

In order to correctly reference this scholarly work, feel free to copy and paste the following:

Guillermo Blugerman, Malcolm D. Paul, Diego Schavelzon, R. Stephen Mulholland, Matthias Sandhoffer, Peter Lisborg, Antonio Rusciani, Mark Divaris and Michael Kreindel (2011). Radio-Frequency Assisted Liposuction (RFAL), Advanced Techniques in Liposuction and Fat Transfer, Prof. Nlkolay Serdev (Ed.), ISBN: 978-953307-668-3, InTech, Available from: http://www.intechopen.com/books/advanced-techniques-in-liposuction-andfat-transfer/radio-frequency-assisted-liposuction-rfal-

\section{INTECH}

open science | open minds

\section{InTech Europe}

University Campus STeP Ri

Slavka Krautzeka 83/A

51000 Rijeka, Croatia

Phone: +385 (51) 770447

Fax: +385 (51) 686166

www.intechopen.com

\section{InTech China}

Unit 405, Office Block, Hotel Equatorial Shanghai

No.65, Yan An Road (West), Shanghai, 200040, China 中国上海市延安西路65号上海国际贵都大饭店办公楼405单元

Phone: +86-21-62489820

Fax: $+86-21-62489821$ 
(C) 2011 The Author(s). Licensee IntechOpen. This chapter is distributed under the terms of the Creative Commons Attribution-NonCommercialShareAlike-3.0 License, which permits use, distribution and reproduction for non-commercial purposes, provided the original is properly cited and derivative works building on this content are distributed under the same license. 